\title{
AN INITIAL DESIGN OF ISO 19152:2012 LADM BASED VALUATION AND TAXATION DATA MODEL
}

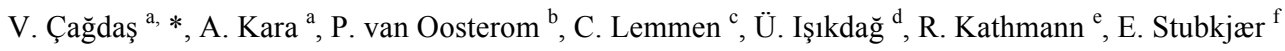 \\ ${ }^{a}$ Y 1 ldız Technical University, Department of Surveying Engineering, 34210 Istanbul, Turkey - (volkan, abkara)@yildiz.edu.tr \\ ${ }^{\mathrm{b}}$ Delft University of Technology, Faculty of Architecture and the Built Environment, Department OTB, GIS Technology Section, \\ P.O. Box 5030, 2600 GA Delft, The Netherlands - P.J.M.vanOosterom@tudelft.nl \\ ${ }^{c}$ Dutch Cadastre, Land Registry and Mapping Agency, Apeldoorn, P.O. Box 9046, 7300 GH Apeldoorn, The Netherlands - \\ chrit.lemmen@kadaster.nl \\ ${ }^{\mathrm{d}}$ Mimar Sinan Fine Arts University, 34427 Istanbul, Turkey - uisikdag@gmail.com \\ ${ }^{\mathrm{e}}$ Netherlands Council for Real Estate Assessment, P.O. Box 93210, 2509 AE The Hague, The Netherlands - \\ r.kathmann@waarderingskamer.nl \\ ${ }^{\mathrm{f}}$ Aalborg University, Department of Development and Planning, 9220 Aalborg, Denmark - est@1and.aau.dk
}

KEY WORDS: Land administration; LADM; property valuation and taxation, fiscal registry

\begin{abstract}
:
A fiscal registry or database is supposed to record geometric, legal, physical, economic, and environmental characteristics in relation to property units, which are subject to immovable property valuation and taxation. Apart from procedural standards, there is no internationally accepted data standard that defines the semantics of fiscal databases. The ISO 19152:2012 Land Administration Domain Model (LADM), as an international land administration standard focuses on legal requirements, but considers out of scope specifications of external information systems including valuation and taxation databases. However, it provides a formalism which allows for an extension that responds to the fiscal requirements. This paper introduces an initial version of a LADM - Fiscal Extension Module for the specification of databases used in immovable property valuation and taxation. The extension module is designed to facilitate all stages of immovable property taxation, namely the identification of properties and taxpayers, assessment of properties through single or mass appraisal procedures, automatic generation of sales statistics, and the management of tax collection, dealing with arrears and appeals. It is expected that the initial version will be refined through further activities held by a possible joint working group under FIG Commission 7 (Cadastre and Land Management) and FIG Commission 9 (Valuation and the Management of Real Estate) in collaboration with other relevant international bodies.
\end{abstract}

\section{INTRODUCTION}

This paper proposes an extension module to the ISO 19152:2012 Land Administration Domain Model (LADM) to be used for the specification of fiscal registries or databases for management of datasets in relation to immovable property valuation and taxation. The module extends LADM according to fiscal requirements derived from international taxation and valuation standards and best practices.

Traditional cadasters as a prototypical form of fiscal registries in Continental Europe are used as a basis for taxation, and together with land registries, they provide geographical and administrative datasets concerning the legal objects required for valuation and taxation. However, cadastral datasets used for identification and registration of legal information in relation to immovable properties, may not be sufficient for today's complex taxation and valuation practices (e.g. computer aided mass appraisal). More specifically, they only provide two dimensional (2D) geometry and legal information about immovable properties, whereas valuation and taxation practices also require three dimensional (3D) geometry not only for the property units but also spatial units (e.g. building units) as addressed by Isikdag et al. $(2014,2015)$ and Atazadeh et al. (2016), and detailed physical and fiscal datasets related to these spatial units. The basic registration unit of cadastral systems (e.g. a cadastral parcel) may also differ from the basic registration units of taxation systems (e.g. a building) whether the details are 2D or $3 \mathrm{D}$. Moreover, the right holder recorded at land registry and taxpayer recorded at taxation databases may be different. These differences require the development of fiscal registries or databases by the relevant authorities to record geometric, legal, physical, economic, and environmental characteristics regarding property units that are the subject of valuation and taxation.

Such a fiscal registry or database may be considered as one of the core registries of national land administration, and, in broader context, public administration. An efficient land administration infrastructure, which aims to enable the management of information concerning the ownership, value and use of land, is further expected to link fiscal registries with other land administration registries such as cadastre, land registry, and address or building and dwelling registries. Such an integration or link between distributed geographic and thematic databases maintained by different organizations can be achieved through geographic information or spatial data infrastructures (SDIs). The domain-independent standards that specify the spatial and temporal aspects of geographical information (e.g. ISO 19107:2003), and domain-specific standards that specify the semantics of a particular domain (e.g. ISO 19152:2012) are one of the main components of the SDI (Lemmen et al., 2011).

There are several international standards related to the procedural aspects of immovable property valuation and taxation, such as European Valuation Standards (TEGoVA, 2012), International Valuation Standard (IVSC, 2013), Mass Appraisal of Real Property (IAAO, 2013a), Ratio Studies (IAAO, 2013b); and measurement standards that specify the area and volume of land,

* Corresponding author 
buildings and building parts for valuation purposes, such as Performance Standards in Building (ISO 9836:2011), International Property Measurement Standards, RICS Code of Measuring Practice, and Area and Space Measurement in Facility Management (BS EN 15221-6:2011). In addition to these procedural standards, the geospatial community has facilitated the development of a number of domain specific data standards that define the 2D and 3D geographical aspects of property units, e.g. ISO 19152:2012 LADM, INSPIRE Data specifications on Cadastral Parcels (INSPIRE D2.8.I.6), Buildings (INSPIRE D2.8.III.2 I) and Land Use (INSPIRE D2.8.III), CityGML (OGC, 2012), IndoorGML (OGC, 2014), draft LandInfra/InfraGML (OGC, 2016).

Despite the existence of the above-mentioned standards, there is no internationally accepted standard that defines the data content or semantics of fiscal databases, such as the entities, attributes/properties, relationships, constraints of the information model. SDI based integration of fiscal databases with other land administration registries or information systems, however, requires the development of a data content standard for fiscal databases. LADM, as an international land administration standard, focuses on legal requirements, but currently excludes the specifications of external information systems including valuation and taxation databases. However, it provides a formalism, which allows for an extension that responds to fiscal requirements. The purpose of the present research, therefore, is to extend LADM from the fiscal point of view to provide a data model that could be used for constructing databases or information systems for fiscal registries.

This research is carried out according to the following methodology by an informal research group consisting of international experts having experience in cadastre and land administration, immovable property taxation and valuation, and geographic information modelling. In the first stage of the methodology, a literature review is performed to define the basic semantics of the fiscal databases, and reveal commonalities and differences in immovable property taxation and valuation applications in different countries. Scholarly literature, and procedural standards, reports and best practices published by IVSC, TEGOVA, IPTI, and IAAO are analyzed in this stage. Moreover, relevant geographic data models (e.g. CityGML, IndoorGML, InfraGML issued by OGC, INSPIRE data specifications) that would provide a framework for the specification of fiscal data model are investigated. Section 2 briefly documents results of these reviews by presenting an international overview to immovable property taxation and valuation practices, and an overview to the pertinent geographical data models. In the second stage, a fiscal data model, as an extension module for LADM (see Section 3 for the details of LADM), is designed through an iterative process according to the findings of the analyses made in the first stage. In addition to specification of ExtValuation and ExtTaxation classes of LADM, some classes and class attributes are adopted from other geographic information standards to more elaborately specify fiscal units and their physical, environmental and economical characteristics needed in taxation and valuation practices. Moreover, some LADM code list classes are extended to cover taxation and valuation specific attribute values. Finally, classes of extension module are associated to corresponding LADM classes. Section 4 describes content of the extension module whose EAP file is also available online at:

http://cadastralvocabulary.org/ladm_fm/ladm_fm.eap. The final stage of the methodology regards dissemination findings of the research with the present article in order to raise an international awareness and community building for the further refinements and national assessments.

\section{AN OVERVIEW OF IMMOVABLE PROPERTY TAXATION AND VALUATION}

Property taxes can be broadly divided into two groups; recurrent taxes in which the taxpayer pays a levy each year; and sporadic taxes which are one-off payments triggered by an event (e.g. sale, inheritance, or gifts). Recurrent taxes include land, building and property taxes while sporadic taxes cover property transfer, inheritance, capital gains, gift, land value increment, betterment, and service taxes (Grover et al., 2015, p. 4). This research regards recurrent taxes on immovable property, defined by the OECD (2010) as 'taxes levied regularly in respect of the use or ownership of immovable property. They are levied on land and buildings, in the form of a percentage of the assessed value of a property or in terms of other characteristics of real property, such as size, location, and so on, from which are derived a presumed rent or capital value' (OECD 2010, p. 295).

Recurrent taxes on immovable property are generally levied on all types of properties; - residential, commercial, industrial, and agricultural. Depending on the jurisdiction, recurrent taxes can be levied on (a) only land or unimproved land (e.g. cadastral parcel), (b) only improvements (e.g. buildings), (c) both land and improvements together, and (d) both land and improvements separately (McCluskey, 1999; Bird and Slack, 2002). Immovable property taxes may be based on monetary value or non-monetary value based measures. In monetary value based systems, tax assessment is based on, for example, market value, annual rental value, or the acquisition price of properties; while in nonmonetary systems assessment is undertaken according to the area or volume value of properties, or using a fixed formula (Youngman and Malme, 1994; McCluskey, 1999; Bird and Slack, 2002; Kitchen, 2003). Tax liability is determined by applying a tax rate to a tax base. Tax rates can be determined by national or municipal governments (Kitchen, 2003, p.30), and fixed in legislation, or annually adjusted for inflation, or determined based on the budgetary needs in each taxation period (Almy, 2001; IAAO, 2010). In many countries, tax rates are differentiated by type or class (e.g. residential, commercial, and industrial), and location of the property (Bird and Slack, 2002).

There are two liability types in immovable property taxation: In rem and in personam. Under in rem liability, the owner who owns the immovable property being taxed is only the taxpayer while in personam liability, the person who owns, occupies, or uses the immovable property is responsible for the tax (Almy, 2001). Often, governments grant exemptions to particular types of property or taxpayer (Bird and Slack, 2002). These exemptions may be granted according to (a) ownership type (e.g. government-owned, occupied property), (b) use type of the property (e.g. charitable, health, educational and religious purposes), and (c) characteristics of taxpayer (e.g. age, disability) (Bird and Slack, 2002).

One of the most important stages of taxation is the assessment of property. In monetary value based systems, the purpose is to determine the tax level of immovable property based upon its relative market value (UNECE, 1996, p. 105). Valuation is an integral part of immovable property taxation; however, it is also employed by public sector actors for several land management activities (e.g. expropriation, and land re-adjustment), as well as private sector actors for real estate financing, investment analysis, and property transactions. The scope of this paper is limited to the valuation activities carried out by public 
organizations for the assessment of properties for immovable property taxation.

Two general valuation approaches are employed in property assessment; single property appraisal and mass appraisal of properties. The former refers to the valuation of a particular property on a given date, while for the latter, it is the process of valuing a group of properties on a given date and using common data, standardized methods, and statistical testing (Gloudemans, 1999 , p. 1). In a single property appraisal, three basic valuation methods, (i) sales comparison, (ii) income capitalization, and (iii) cost methods, are applied. The sales comparison method compares the subject property with other similar properties that have been recently sold. It estimates the value of the subject property by making adjustments in the sales prices of the comparable properties in terms of their differences from the subject property. Adjustments are usually made for the time of sale, location and physical characteristics (IAAO, 1996, p. 105). The income method converts the present or prospective stream of income derived from property into capital value through several approaches, for example, direct capitalization and yield capitalization (Shugrue, 1963). The cost method requires an estimate of the current cost to reproduce or replace a building and the extent to which building has depreciated. Reproduction or replacement cost, less depreciation, plus land value determines value of the property.

In contrast to single property appraisal, mass appraisal uses statistical models (e.g. additive, multiplicative, hybrid models) that explain the supply and demand of the property market, and statistical methods (e.g. multiple regression analysis, neural networks, adaptive estimation procedure) to analyze these models based on input datasets with relevant properties. In general, these models are the form of standardized sales comparison using a model describing the object characteristics (the similarities and differences of the properties to be valued) and how these characteristics influence prices in the real estate market. It may also include a performance analysis stage, called a 'ratio study' to compare the appraised values with market values in order to determine the accuracy of the appraisal. The following two accuracy aspects are measured; appraisal level and appraisal uniformity. The former refers to the overall or typical ratio of the appraised values to the market values. The appraisal level is ascertained by central tendency measures such as, mean, median, weighted mean. Appraisal uniformity refers to the appraisal consistency and equity between and within groups of properties. It could be expressed for instance, by the coefficient of dispersion, coefficient of variation, or price-related differential measures (Gloudemans, 1999).

The following section summarizes the content of LADM, which is taken as the basis for the development of the fiscal data model.

\section{LAND ADMINISTRATION DOMAIN MODEL}

LADM is an abstract model that focuses on the legal and geographical aspects of land administration. In particular, it aims to standardize cadastral systems, while the domain of land administration is expected to other land-related public registries (e.g., address, land use and land cover, property taxation, and valuation databases). The conceptual data model of ISO 19152 LADM consists of the following three packages: (1) Administrative Package, (2) Spatial Unit Package, and (3) Party Package.

The Administrative Package (see Figure 1) defines the recording units of land administration with the term of 'basic administrative unit' which corresponds to the 'basic property unit' in UNECE (2004) terminology. LA_BAUnit refers to an 'administrative entity, subject to registration (by law), or recordation, consisting of zero or more spatial units against which (one or more) unique and homogeneous rights, responsibilities or restrictions are associated with the whole entity, as included in a land administration system' (ISO 19152 LADM, p. 2). LA_BAUnit has attributes that specify name, type and identifier of the basic administrative units. It is associated with LA_RRR that covers instances of rights (LA_Right), restrictions (LA_Restriction), and responsibilities (LA Responsibility) according to formal (e.g. common law, civil law) and informal (e.g. customary) legal systems.

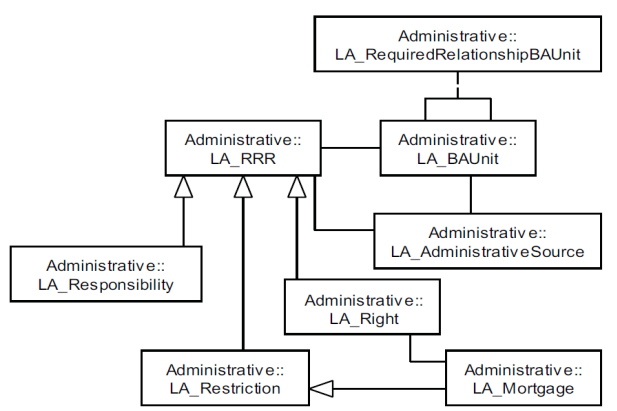

Figure 1. Classes of the Administrative Package (ISO 19152:2012, p. 10)

The Spatial Unit Package and its Surveying and Representation sub-packages deal with spatial units (e.g. cadastral parcel, legal space building units, and legal space utility networks), and their geometric/topological representation based on ISO and OGC standards (see Figure 2 and Figure 3). As shown in Figure 3, the class is LA_SpatialUnit that specifies 'single area (or multiple areas) of land and/or water, or a single volume (or multiple volumes) of space' (ISO 19152:2012 p. 6). Its specialized subclasses LA_LegalSpaceBuildingUnit and LA_LegalSpaceUtilityNetwork allow for the representation of legal spaces related to building units and utility networks, respectively.

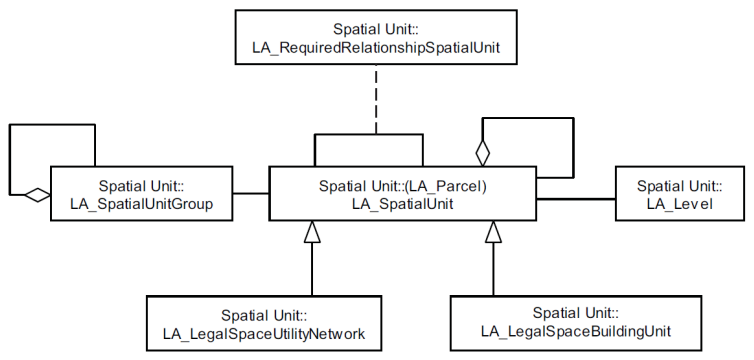

Figure 2. Contents of the Spatial Unit Package (ISO 19152:2012, p. 10). 


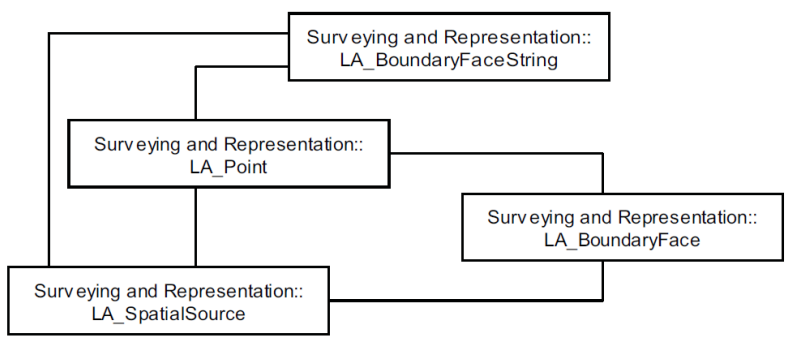

Figure 3. Contents of the Surveying and Representation subpackages (ISO 19152:2012, p. 11)

The Party Package includes the LA_Party class, which represents natural and legal people, and the LA_GroupParty class representing the groups consisting of a number of parties both of which play a role in land administration (Lemmen, 2012, p. 96).

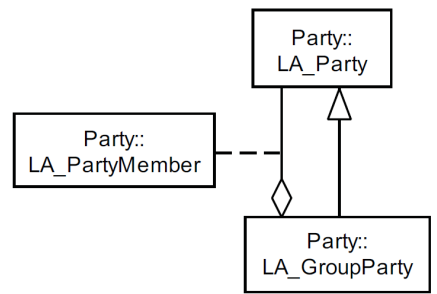

Figure 4. Contents of Party Package (ISO 19152:2012, p. 9)

As mentioned above, LADM does not standardize valuation and taxation data. However, it does provide external classes (stereotype $<<$ blueprint $>>$ ) for these datasets, which indicate the dataset elements LADM expects from these external sources based on information models as specified in other standards (Lemmen et al., 2011). Figure 5 presents an overview of the external classes in relation to the LADM core classes.

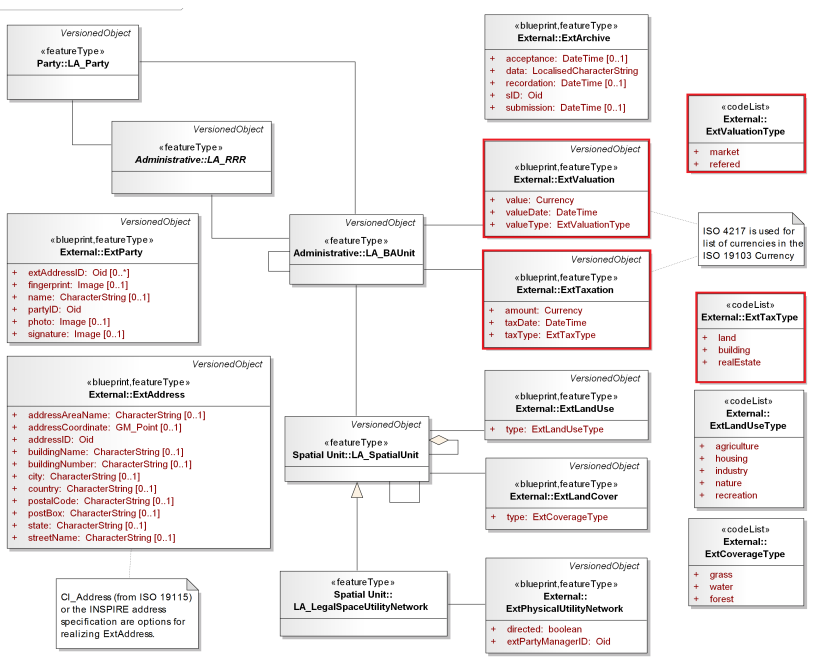

Figure 5. External LADM classes (ISO 19152:2012, p. 104).

The next section focuses on the specification of the ExtValuation and ExtTaxation classes of LADM to propose an LADM compliant fiscal data model for taxation and valuation databases and information systems.

\section{AN INITIAL DESIGN OF LADM-BASED FISCAL DATA MODEL}

This section describes the initial version of a fiscal data model, labelled with the prefix FM and developed through the specification of the ExtValuation and ExtTaxation classes of LADM, in addition to the new classes, class attributes, and relationships, as well as the constraints. It provides a base model for recording data concerning the fiscal parties involved in the valuation and taxation practices, fiscal units that are the objects of valuation and taxation, and their characteristics required in valuation and taxation applications (see Figure 6). It is noted that the extension module focuses on administrative valuations in relation to property tax assessments, and excludes other public and private sector valuation activities.

There are different taxation approaches across the world. Most countries tax both land and buildings under a single tax; however, in some countries two different taxes are levied; unimproved land tax, and an immovable property tax (e.g., Australia, New Zealand, Poland, Slovak Republic, Brazil), and a building tax and an immovable property tax (e.g. Greece, Ireland, and United Kingdom) (Almy, 2014). Therefore, the objects of taxation and valuation may be; (i) immovable property including cadastral parcels, buildings and other fixtures, (ii) only cadastral parcels, (iii) only buildings, or (iv) condominium units with privately owned building parts.

These objects are related to the LA SpatialUnit, LA_LegalSpaceBuildingUnit and LA_BAUnit classes in LADM from the legal and cadastral point of view. The LA_SpatialUnit class and LA LegalSpaceBuildingUnit focus on the spatial representation of cadastral parcels and legal building units, respectively. They are further used to form the immovable properties represented with the LA_BAUnit class, such as one or more parcels with/without buildings and fixtures, and condominium units. These designations of LADM provide a base for the specification of fiscal objects; however, they should be supported from a fiscal point of view.

A cadastral system is generally organized to maintain legal information in relation to immovable properties (i.e., one or more parcels and attached buildings, and condominium units) whereas a fiscal database is organized in a way that stores information in relation to parcels, buildings, parcels and buildings together, and condominium units since these components may, individually, be the object of valuation and taxation procedures. Therefore, the developed extension module proposes a parent FM_FiscalUnit class, and FM_Parcel, FM_AbstractBuilding, FM CondominiumUnit subclasses to represent parcels, buildings and condominium units, and their physical and fiscal characteristics required by the valuation and taxation authorities, as illustrated in Figure 6.

FM_FiscalUnit represents the basic recording unit of fiscal registries is associated with LA_BAUnit, which denotes the basic registration unit of cadastral systems. Owing to the constraints created for the fiscalUnitType attribute of the FM_FiscalUnit class, the extension module enables the recording of data only for the selected fiscal units according to the selected tax base (i.e., only parcels, or only buildings, or parcels and buildings together, or condominiums). For instance, when the tax base only refers to parcels, then the first constraint determines that a fiscal database records information only for parcels and disregards buildings and condominium units. Similarly, the second constraint enables recording of only information concerning buildings when the tax basis only pertains to buildings. 


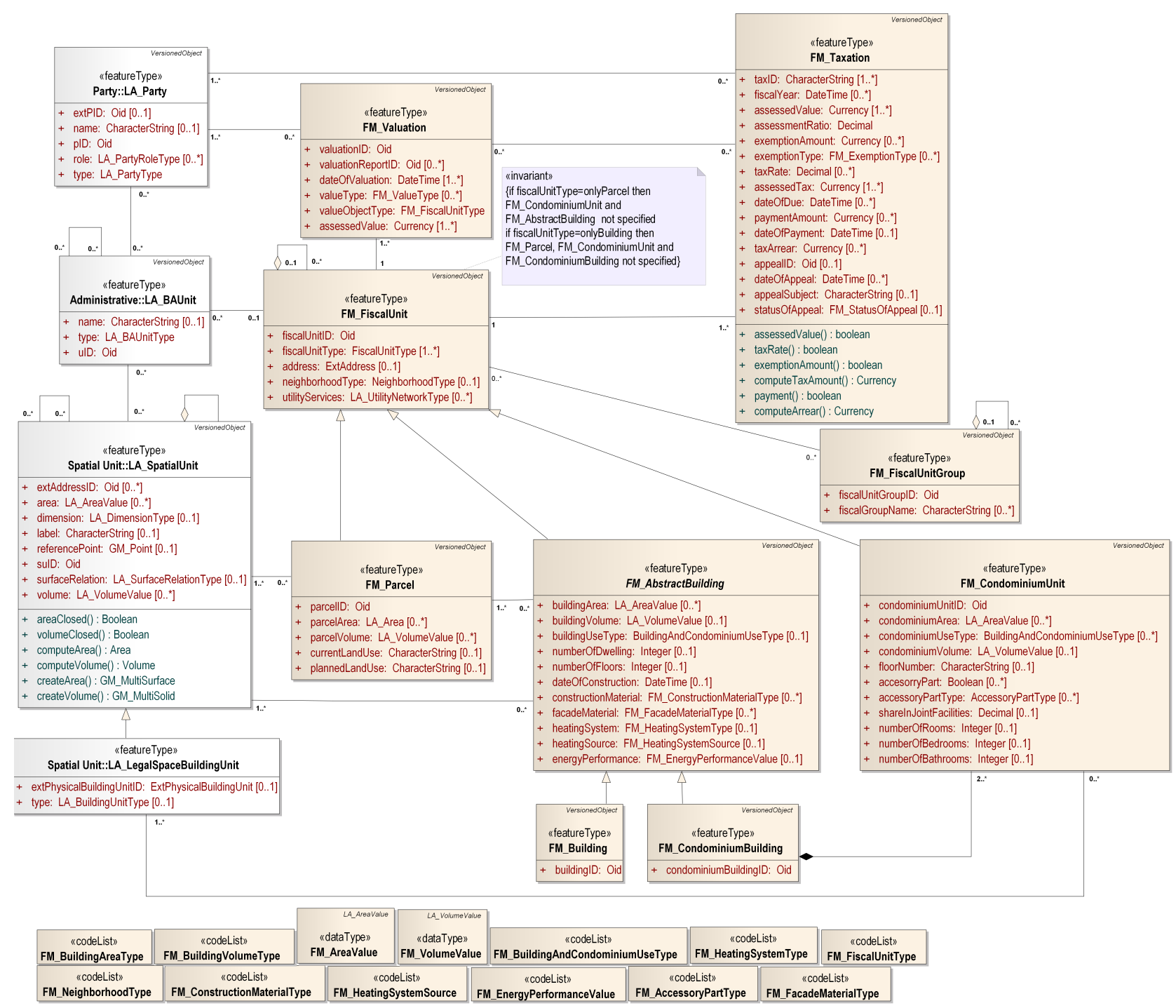

Figure 6. Core classes of fiscal extension module

The FM_FiscalUnit class defines common characteristics for the fiscal objects through attributes, such as identifier, fiscal unit type, address, neighborhood type, and available utility services. Among these, the neighborhoodType attribute is used to denote the type of neighborhood where the fiscal unit is located (e.g., urban, rural), and the utilityServices attribute records the available utility services (e.g., natural gas, electricity), enumerated in the FM_NeighborhoodType and LA_UtilityNetworkType code list classes, respectively.

The FM_Parcel class represents cadastral parcels, as well as subparcels that are the division of parcels based on official land use for taxation purposes (e.g., France and Spain). In addition to inherited attributes from FM_FiscalUnit, it has attributes for parcel identifiers recorded in the cadastral information system including area, current and planned land uses. The current land use attribute is used to denote the existing use of a cadastral parcel while planned land use is used to show the future use of a parcel indicated by spatial plans (INSPIRE D2.8.III.4). The Hierarchical INSPIRE Land Use Classification System (HILUCS) provides a code list for both existing and planned land use attributes.
For different taxation practices, fiscal units may be grouped according to zones (e.g., central business districts, administrative divisions, value zone) that have similar environmental and economic characteristics, or categorized according to functions and types of fiscal units (e.g., commercial, residential, agricultural) that have similar physical characteristics. Moreover, mass appraisal models and 'ratio study analysis' may be employed for such groups instead of individual units. This issue is addressed by the FM FiscalUnitGroup class in the extension module, which includes an identifier and type attributes. It should be noted that FM_FiscalUnitGroup not only groups spatially related fiscal units, but also spatially unrelated units that have similar characteristics, e.g., commercial properties.

LADM is only concerned with the legal space of buildings and building parts (e.g., individually owned apartments, jointly owned building parts), which does not necessarily coincide with the physical space of a building (ISO 19152:2012, p. 11). LADM also relates the legal space of building units with the corresponding physical building units recorded at external databases through the LA_LegalSpaceBuildingUnit class. Two data models, INSPIRE Data Specification on Buildings (INSPIRE D2.8.III.2) and CityGML (OGC, 2012) provide a framework for the development of such external databases. 
Incorporating their approach, an abstract FM_AbstractBuilding class is included in the extension module to specify buildings, building parts, and their physical characteristics that are needed for valuation procedures. FM AbstractBuilding provides a set of common attributes shared by its sub-classes, such as area, volume, type of use, building type, number of dwellings and floors of buildings. It also accommodates construction and energy related attributes, i.e. date of construction, construction material, facade material, heating system, heating source and energy performance. Figure 7 shows the code list classes that present values for the mentioned attributes, such as FM_BuildingAndCondominiumUseType,

FM_ConstructionMaterialType, FM_FacadeMaterialType, FM_HeatingSystemSource, FM_HeatingPerformanceType, and FM_EnergyPerformanceValue.

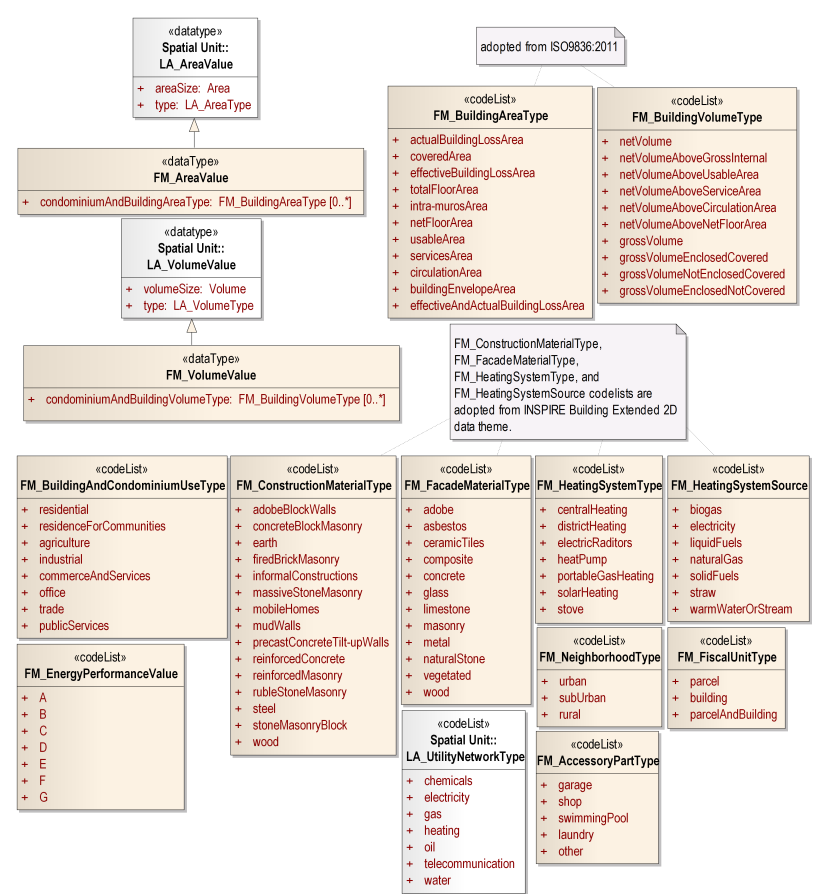

Figure 7. Data types and code list classes for the FM_FiscalUnit class and its subclasses

In LADM, the LA_AreaValue and LA_VolumeValue data types, and the LA AreaType and LA_VolumeType code lists support the recording the various types of area and volume values (e.g., calculated, official) of spatial units. In the proposed module, these data types are extended with FM_AreaValue and FM_VolumeValue to specify different types of area and volume values of buildings and condominium units (e.g., total floor area, gross volume). The area and volume types defined in the ISO Performance Standards in Building (ISO 9836:2011) are adopted via the FM_BuildingAreaType and FM_BuildingVolumeType code list classes.

FM_AbstractBuilding has two concrete classes, FM_Building FM CondominiumBuilding. The former represents buildings that are considered as complementary parts of parcels, but may be taxed or valued separately from the parcels on which they are located. The latter, FM_CondominiumBuilding, is taken from the OGC's draft LandInfra/InfraGML standard to specify buildings that contain condominium units established according to condominium schemes (OGC, 2016, p. 209). Both classes inherit attributes from the FM_AbstractBuilding class.
A condominium building consists of (i) condominium units (e.g. flats, shops); (ii) accessory parts assigned for exclusive use by specific condominium units (e.g. garages, storage areas); (iii) and joint facilities covering parcel, structural components (e.g. foundations, roofs), accession areas (e.g. entrance halls, spaces), and other remaining areas of buildings (e.g. staircases, heating rooms). Joint facilities are owned collectively by all the owners of the condominium units according to ownership shares of the condominium units, while accessory parts and the main condominium units are owned individually by the owners of these units (OGC, 2016; Çağdaş, 2013). The extension module proposes an FM_CondominiumUnit class to record the main condominium unit characteristics needed for valuation procedures, such as area and volume, use type, type of condominium, floor number, and number of rooms, bathrooms and bedrooms. Condominium valuation and taxation, however, regards not only the main condominium units, but also the related accessory parts and shares in joint facilities. Therefore, FM_CondominiumUnit is supported with a shareInJointFacilities attribute to indicate share of condominium unit in commonly owned areas, with the accessoryPart and accessoryPartType attributes that specify the existence and type of accessory parts (e.g. garage, swimming pool) allocated to the condominium units.

The next two classes, FM_Valuation and FM_Taxation, as counterparts of ExtValuation and ExtTaxation external classes of LADM, are created to specify valuation and taxation information. The relationships between FM_Valuation, FM_Taxation, LA Party and FM FiscalUnit indicate that a fiscal unit may be subject to one or more tax that may be levied on one or more taxpayers, and hence be the subject of one or more valuation activities carried out by one or more valuation experts.

As shown in Figure 8, the FM_Valuation class focuses on the input and output data used and produced within single or mass appraisal processes for property tax assessment. It identifies valuation activities and valuation reports through valuationID and valuationReportID attributes, indicates the valuation date and value type with valuationDate and valueType attributes, and the final assessed value with the assessedValue attribute. Generally, the value of a fiscal unit may be estimated by different approaches and methods before the final assessment, such as sales comparison, cost and capitalization methods in single property appraisal or mass appraisal procedures. FM SinglePropertyAppraisal created as a subclass of FM_Valuation aims to describe single property appraisal related details using a number of attributes, i.e., valuationBySalesComparisonMethod, valuationByCostMethod, valuationByIncomeMethod, and the corresponding data type classes given in Figure 9.

The FM SalesComparisonMethod data type supports the documentation of comparable fiscal units used in the sales comparison approach, and monetary adjustments made for the sale according to the time, location, physical and environmental differences from comparable units to estimate value of subject unit. The FM_CostMethod data type organizes the cost method related details, such as type (e.g., replacement or reproduction cost), source and price of cost, chronological and effective age of improvements, and appreciated depreciations (e.g., physical, functional, external and total depreciations) occurring through the improvements. The FM_IncomeMethod data type renders the potential gross, effective gross and net incomes, operating expenses, capitalization and discount rates, and gross rent multipliers used in the direct and yield capitalization approaches of income capitalization procedures. 


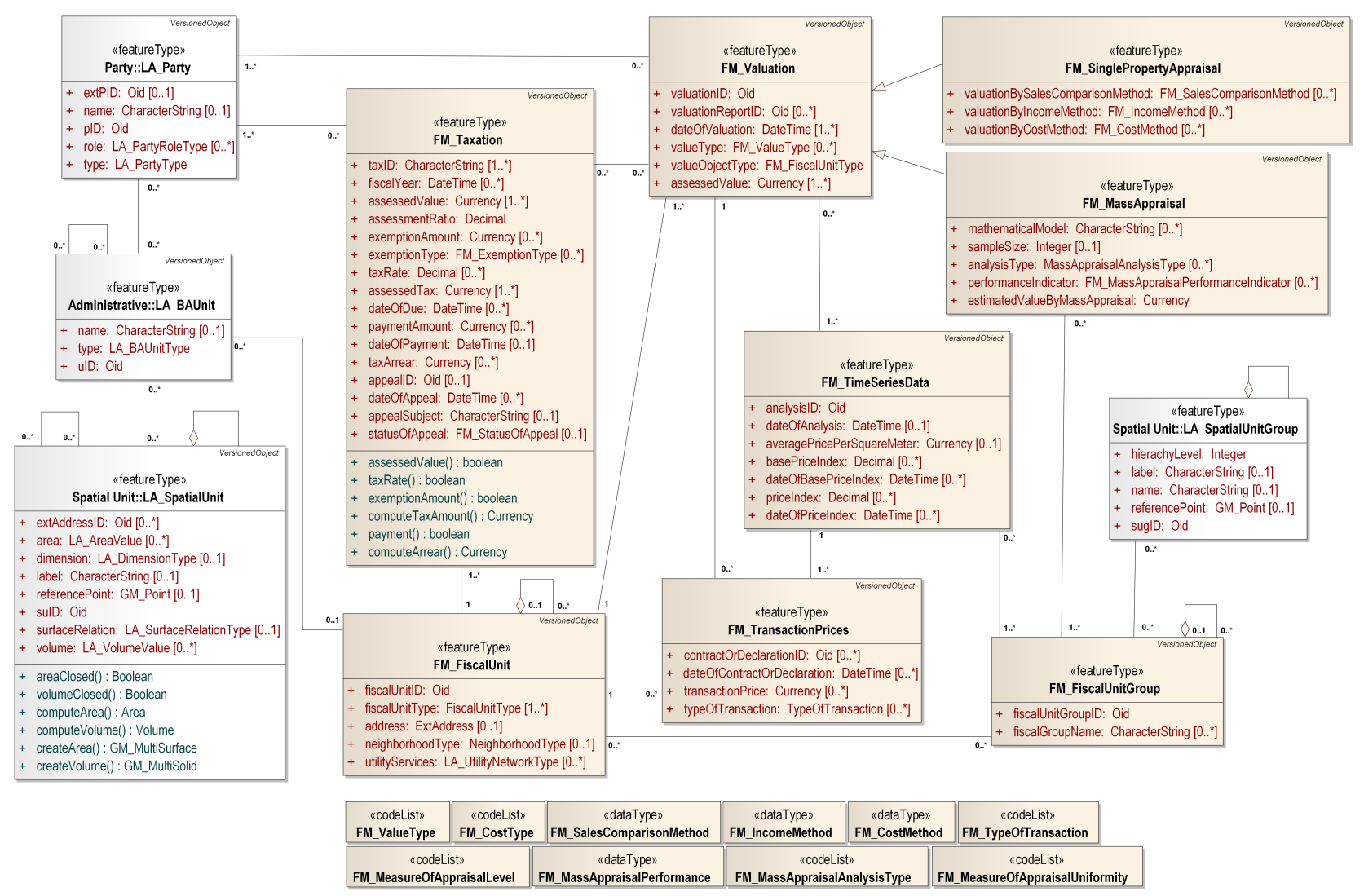

Figure 8. FM_Valuation and related classes

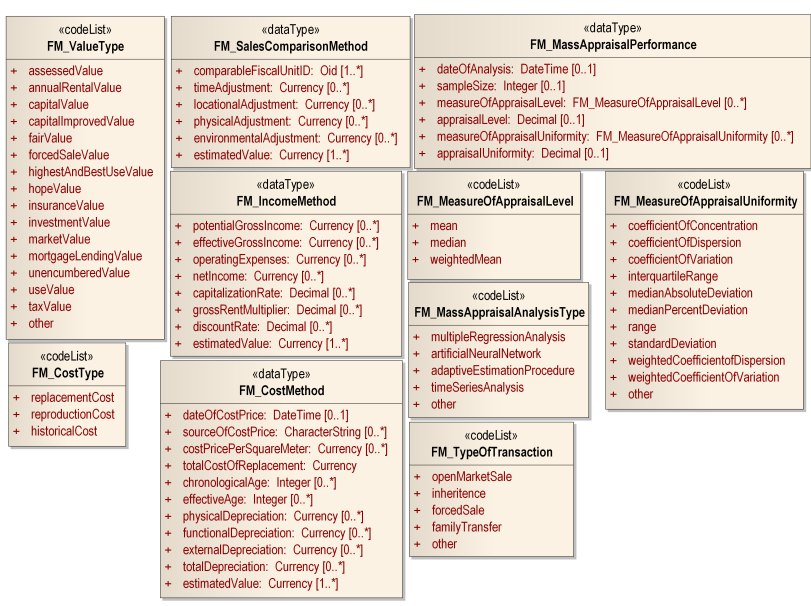

Figure 9. Code list and data type classes developed for FM_Valuation and its subclasses

The other subclass of FM_Valuation, FM_MassAppraisal is designed to organize mass appraisal-related information. Specifically, it describes mathematical models, mass appraisal analysis types (e.g., multiple regression analysis), and the sample size of the analysis. It also has a performance indicator attribute and corresponding FM_MassAppraisalPerformance data type. The date of performance analysis, sample size, measures for appraisal level (e.g., mean), appraisal uniformity (e.g., coefficient of dispersion), and values for the selected measurements can be recorded through the FM_MassAppraisalPerformance data type class.
Many countries maintain registers or databases to record data in relation to property transactions, such as the Sales and Valuation Register in Denmark, Purchase Price Collection in Germany, Price Paid Data in the United Kingdom, and sales prices as part of the cadastral information in the Netherlands. In order to support single and mass appraisal procedures, these databases are used to produce periodic sale statistics and price indexes (e.g., Purchase Price Statistics of Real Estates in Finland, House Price Index in the United Kingdom, and the Price Index for existing houses in the Netherlands) that show the total amount and type of transactions, average values, and changes in property values. Such registers or databases are created and updated regularly by information provided from contracts or declarations submitted by the parties (e.g. buyer and/or seller) involved in the property transactions. The fiscal extension model is supported by the FM_TransactionPrices and FM_TimeSeriesData classes to address information regarding transaction prices and statistics, respectively. FM_TransactionPrices is provided with attributes that characterize the information content of transaction contracts or declarations, including the date of contract or declaration, price, date and type of transaction (e.g., sale, heritage, forced sale, and rent prices). The next class, FM_TimeSeriesData, is created to represent time series data produced through the analysis of transaction prices. It is related to FM_FiscalUnitGroup since such analysis can be made based on spatial (e.g. parcels in a municipality) or thematic clusters (e.g., parcels used for agricultural purposes) of fiscal units. In addition to identifier and date attributes, it has attributes to indicate the calculated average transaction prices per square meter of fiscal units. 


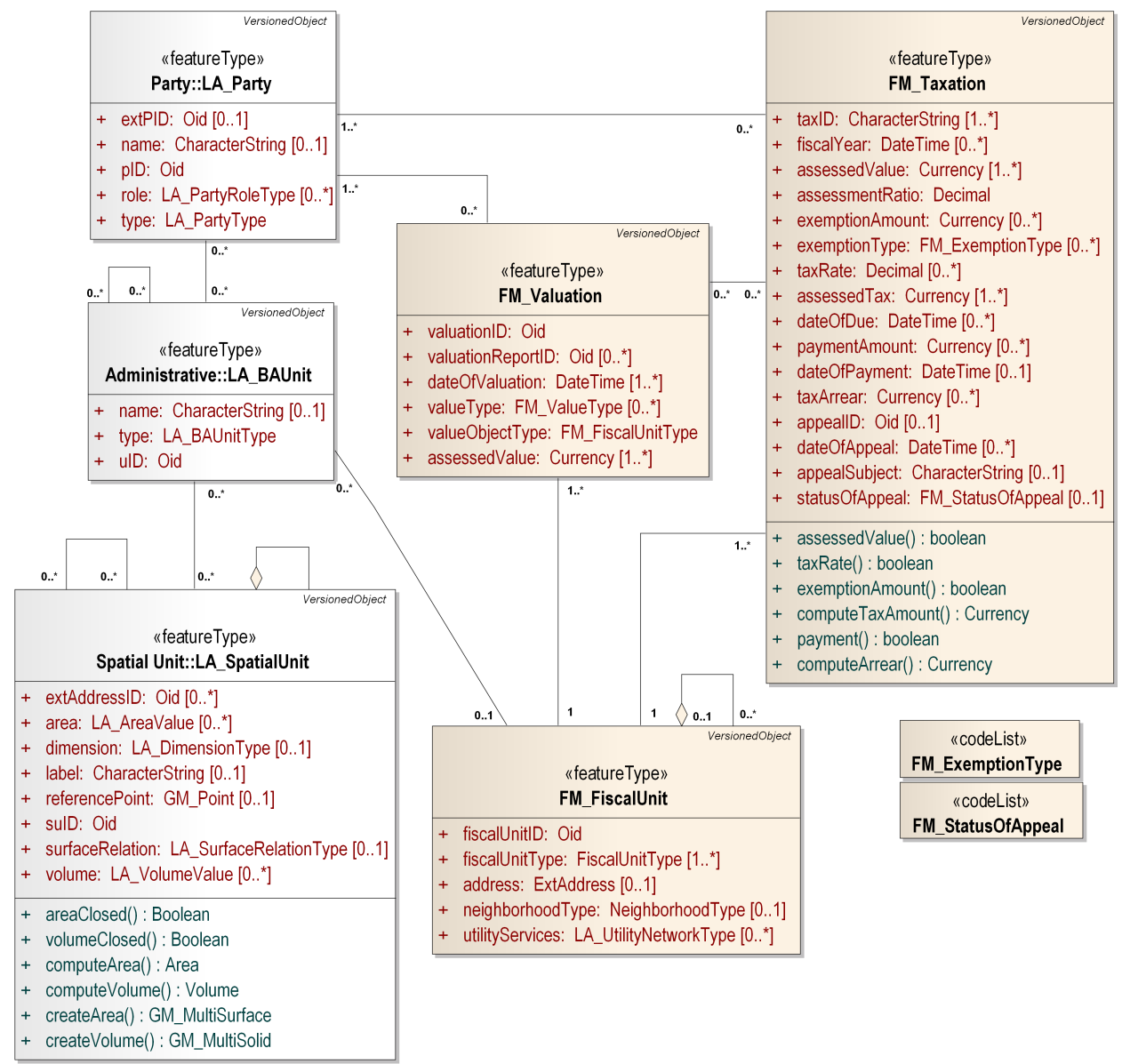

Figure 10. FM_Taxation and related classes

Moreover, it has basePriceIndex and dateOfBasePriceIndex attributes to record the value and date for specification of base index (e.g. Base Index Value $=100$ at 2015 January), and priceIndex and dateOfPriceIndex attributes to record the calculated price index at a given date (e.g. Index Value $=120$ at 2016 January). Transaction prices and transaction statistics recorded through FM TransactionPrices and FM_TimeSeriesData are directly used in single and mass appraisal procedures, as indicated by two associations from FM_Valuation to FM_TransactionPrices and FM_TimeSeriesData.

The next class, FM_Taxation with LADM ExtTaxation, focuses on the recording of taxation specific information, such as the name or identifier of immovable property tax, fiscal year, assessed value of the fiscal unit, type and amount of exemptions granted, assessment ratio and tax rates applied, assessed tax and its due date, and details regarding payments and appeals (e.g., payment amount, payment date, appeal id, subject of appeal, and status of appeal). Two code list classes, FM_ExemptionType and FM_StatusOfAppeal, provide values for the exemptionType and AppealStatus attributes, respectively (see, Figure 10 and Figure $11)$.

The LA_Party class in LADM represents the natural and legal persons, and groups consisting of a number of parties both of which play a role in land administration. It can also be utilized to record information about parties that are involved in or affected by valuation and taxation procedures.
The LA_PartyRoleType code list class, which provides values for the role performed by the parties (e.g., surveyor or notary) in the land administration domain, is therefore extended in the fiscal module to cover valuation and taxation-related roles, such as taxpayers and appraisers.

\begin{tabular}{|l|l|l|}
\hline \multicolumn{1}{|c|}{$\begin{array}{l}\text { «codeList» } \\
\end{array}$} & FM_ExemptionType \\
\hline+ & personalExemption \\
+ & governmentalExemption \\
+ & charitableExemption \\
+ & religiousExemption \\
+ & other
\end{tabular}

Figure 10. Code list classes developed for the FM_Taxation

Finally, the temporal aspect in the extension module is addressed with the VersionedObject class and a number of attributes assigned to the FM_Valuation and FM_Taxation classes. In LADM, VersionedObject is the superclass of all classes either directly or indirectly, and has the beginLifespan and endLifespan attributes to specify the date and time when the object was inserted, changed, and removed from the database. In keeping with the LADM design approach, all classes in the fiscal data module are created as a subclass of VersionedObject either directly (e.g., FM_FiscalUnit, FM_Taxation, FM_Valuation) or indirectly (e.g., FM Parcel, FM Building, FM MassAppraisal). Moreover, several attributes are assigned to the FM_Valuation and FM_Taxation classes to deal with other temporal issues in 
relation to fiscal procedures, e.g., fiscal year, date of due, date of payment and date of appeal for taxation procedures; and date of valuation, date of cost for valuation procedures.

\section{CONCLUSIONS}

This article describes a fiscal data model for the specification of inventories or databases used in immovable property valuation and taxation. As an extension module of ISO 19152:2012 Land Administration Domain Model, it is designed to facilitate all stages of immovable property taxation, namely the identification of properties and taxpayers, assessment of properties through single or mass appraisal procedures, automatic generation of sales statistics, and the management of tax collection, dealing with arrears and appeals. More specifically, it enables the recording of data concerning the fiscal parties that are involved in valuation and taxation practices, fiscal units that are subject of valuation and taxation, as well as their characteristics. The extension module also supports the integration of legal datasets recorded in cadastral systems and fiscal datasets recorded at fiscal databases or inventories. Such standardization of valuation and taxation databases provides governments with a common basis for the development of local or national databases, and a guide for the private sector to develop information technology products. Within the theoretical framework and outcomes of international efforts in terms of international standards, best practice documents and scholarly literature on immovable property valuation and taxation have been reviewed, consolidated and incorporated in this initial version. It is expected that this initial design will be refined through further research and activities held by a possible joint working group under FIG Commission 7 (Cadastre and Land Management) and FIG Commission 9 (Valuation and the Management of Real Estate) in collaboration with other relevant international bodies, such as OGC, TEGOVA, IVSC, IPTI and IAAO. The proposed module is planned to be included in LADM 2.0, the revised future version of LADM to be issued after ISO's periodic maintenance procedure in 2017. The future work includes elaboration of the proposed model by investigating and adopting designations of the relevant data modeling initiatives (e.g. CityGML Energy $\mathrm{ADE}$ ); assessment of the proposed model via instance level example diagrams from various countries; implementation of a prototype system with actual data; and presenting a more detailed description of model semantics (e.g. classes, attributes, relationships, and constraints) as a part of LADM 2.0.

\section{REFERENCES}

Almy, R., 2001. A Survey of Property Tax Systems in Europe. Report prepared for the Department of Taxes and Customs, Ministry of Finance, Republic of Slovenia.

Almy, R. 2014. Valuation and Assessment of Immovable Property, OECD Working Papers on Fiscal Federalism, No. 19, OECD Publishing, Paris.

Bird, R. M. and Slack, E., 2002. Land and Property Taxation: A Review. World Bank, Washington, DC.

BS EN 15221-6:2011 - Space and Area Measurement in Facility Management, 2011-10-19.

BS ISO 9836:2011 - Performance standards in building Definition and calculation of area and space indicators, 2011- 1001 .
Gloudemans, R.J. 1999. Mass appraisal of real property. Kansas City: International Association of Assessing Officers.

Grover, R., Törhönen, M.P., Munro-Faure, M., Anand, A., 2015. Property valuation and taxation for fiscal sustainability and improved local governance: case studies from the ECA region. World Bank Conference on Land and Poverty. The World Bank - Washington DC, March 23-27.

IAAO, 2010. Standard on Property Tax Policy. Kansas City, Missouri.

IAAO, 2013a. Standard on Mass Appraisal of Real Property. Kansas City, Missouri.

IAAO, 2013b. Standard on Ratio Studies. Kansas City, Missouri.

INSPIRE D2.8.III.2. INSPIRE Data Specification on Buildings Draft Technical Guidelines, v3.0rc3, 2013-02-04.

INSPIRE D2.8.III.4 INSPIRE Data Specification on Land Use Guidelines, v3.0, 2013-12-10.

IPMS, 2014. International Property Measurement Standards (IPMS): Office Buildings.

Isikdag, U., Horhammer M., Zlatanova S., Kathmann R., and van Oosterom P., 2014. Semantically Rich 3D Building and Cadastral Models for Valuation. 4th International Workshop on 3D Cadastres, 9-11 November 2014, Dubai, United Arab Emirates.

Isikdag, U., Horhammer M., Zlatanova S., Kathmann R., and van Oosterom P., 2015. Utilizing 3D Building and 3D Cadastre Geometries for Better Valuation of Existing Real Estate. FIG Working Week 2015, From the Wisdom of the Ages to the Challenges of the Modern World, Sofia, Bulgaria, 17-21 May 2015.

ISO 19107:2003 Geographic information -- Spatial schema. International Organization for Standardization (ISO), Geneva.

ISO TC/211 - ISO 19152:2012. Geographic information - Land Administration Domain Model (LADM).

IVSC, 2013. International Valuation Standards. London, United Kingdom.

Kitchen, H., 2003. Property Taxation: Issues in Implementation. The Consortium for Economic Policy Research.

Lemmen, C. H. J., Van Oosterom, P. J. M., Uitermark, H. T., Zevenbergen, J. A., and Cooper, A. K., 2011. Interoperable domain models: The ISO land administration domain model LADM and its external classes. In UDMS 2011: 28th Urban Data Management Symposium, Delft, The Netherlands, September 28-30, 2011.

Lemmen, C.H.J., 2012. A domain model for land administration. $\mathrm{PhD}$ Thesis Technical University Delft. ITC Dissertation 210, ISBN: 978-90-77029-31-2.

McCluskey, W.J., 1999. Comparative Property Tax Systems: An International Comparative Review. Aldershot, UK: Avebury Publishing Limited.

OECD, 2010. Revenue Statistics 1965-2010: 2010 Edition. 
OGC, 2012. OpenGIS City Geography Markup Language (CityGML) Encoding Standard (Version 2, Publication Date: 2012-04-04).

OGC, 2014. Indoor GML (Version 1, Publication Date: 2014- 0202).

OGC, 2016. Land and Infrastructure Conceptual Model Standard (LandInfra). Draft Distribution. (Version 1.0, Date: 2016-07-01).

RICS, 2007. Code of Measuring Practice, 6th edition, Coventry, UK.

Shugrue, F.R., 1963. The nature of real estate appraisal. In Encylopedia of Real Estate Appraising (Ed. E.J. Friedman), Fifth edition, Prentice-Hall: Englewood Cliffs, N.J., pp. 3-14.

TEGoVA (2012). European Valuation Standards (EVS). $7^{\text {th }}$ Edition. Gillis: Belgium.

UNECE, 1996. Land Administration Guidelines. UNECE, United Nations, New York and Geneva.

UNECE, 2004. Guidelines on Real Property Units and Identifiers. UNECE, United Nations, New York and Geneva.

Youngman, J. and Malme, J., 1994. An International Survey of Taxes on Land and Buildings. Boston: Kluwer Law and Taxation Publishers. 